\title{
Perovskite-Type Oxides $\mathrm{La}_{0.6} \mathrm{M}_{0.4} \mathrm{Ni}_{0.6} \mathrm{Cu}_{0.4} \mathrm{O}_{3}(\mathrm{M}=\mathrm{Ag}, \mathrm{Ba}, \mathrm{Ce})$ towards the Oxygen Reduction Reaction (ORR) in Alkaline Medium: Structural Aspects and Electrocatalytic Activity
}

\author{
Alan R. F. Lima, ${ }^{\oplus a}$ Alex S. Lima, ${ }^{a}$ Gabriel N. Meloni, ${ }^{a}$ Carla S. Santos ${ }^{a}$ and \\ Mauro Bertotti ${ }^{\odot}, a$ \\ ${ }^{a}$ Departamento de Química Fundamental, Instituto de Química, Universidade de São Paulo, \\ 05508-000 São Paulo-SP, Brazil
}

\begin{abstract}
In this work, $\mathrm{La}_{0.6} \mathrm{M}_{0.4} \mathrm{Ni}_{0.6} \mathrm{Cu}_{0.4} \mathrm{O}_{3}(\mathrm{M}=\mathrm{Ag}, \mathrm{Ba}$, and $\mathrm{Ce}$, denoted as LANC, LBNC, and LCNC, respectively) electrocatalysts were synthesized by the Pechini method at $1023 \mathrm{~K}$ for two hours in air. Rietveld refinement allowed the identification of the crystallographic phases present in all oxides. The electrocatalytic performance of these oxides towards the oxygen reduction reaction (ORR) was examined in alkaline medium by rotating disk electrode (RDE) technique and scanning electrochemical microscopy (SECM) in the redox competition mode. The results indicate that the best performance was found with the LANC electrocatalyst prepared with carbon as a conducting agent (LANC/Carbon), which showed good catalytic activity towards the ORR via a pseudo fourelectron transfer pathway. The enhanced electrocatalytic activity of LANC is probably a result of the presence of a $\mathrm{Ag}$ phase, which improves the synergistic effect between the perovskite and carbon added to increase the conductivity, thus leading to a higher ORR performance when compared to other materials.
\end{abstract}

Keywords: oxygen reduction reaction, perovskite oxides, electrocatalytic performance, synergistic effect, secondary phase

\section{Introduction}

Owing to the shortage of non-renewable energy sources, such as petroleum and natural gas, the search for energy derived from alternative sources has received increased attention. Considering this scenario, the development of renewable energy production and storage technologies is one of the most significant scientific challenges of the twenty-first century. ${ }^{1,2}$ Accordingly, it is not surprising that massive efforts have been made to discover more efficient and cost-effective catalysts for the use in electrochemical energy conversion processes. ${ }^{3,4}$

Several types of devices based on oxygen electrochemistry have been reported in the literature, such as both direct-solar, ${ }^{5}$ and electrolytic water-splitting, ${ }^{6-8}$ fuel cells, ${ }^{9,10}$ and metal-air batteries. ${ }^{11-13}$ However, the oxygen reduction reaction (ORR) is the kinetically limiting step, and efforts have been taken to trigger such a process as close to the reversible conditions as possible (i.e., with an overpotential close to zero). ${ }^{14}$ To improve the efficiency

*e-mail: mbertott@iq.usp.br of these devices, huge efforts have been devoted towards a better understanding of the composition and structural aspects of electrocatalysts, such as synthesis methods, defects, and reaction conditions. ${ }^{15-19}$

Currently, precious metals such as platinum and gold are the most used in the synthesis of electrocatalysts due to their high activity towards ORR. ${ }^{20-24}$ However, the high cost and scarcity of these metals have severely limited their application in practical devices. ${ }^{25,26}$ As a replacement strategy, La-based perovskite oxides have shown reasonably high activity for the ORR in fuel cells, ${ }^{27-30}$ oxygen evolution reaction (OER) in water electrolysis, ${ }^{7,31-34}$ and direct solar water splitting, ${ }^{35,36}$ hence they constitute a low-cost alternative to the use of noble metals.

A schematic representation of perovskite-type mixed oxides, which have the general formula $\mathrm{ABO}_{3}$, is shown in Figure 1, where A is located in the cubic center and B in the octahedral, occupied cubic vertices. ${ }^{37}$ The A sites (yellow balls) can be occupied by large cations (i.e., La and $\mathrm{Ba}$ ), and cations with smaller ionic radii (i.e., $\mathrm{Ni}$ and $\mathrm{Cu}$ ) occupy B sites (green balls). Unlike metal catalysts, whose ORR rate depends on acidic environments, La-based 
perovskite oxides require alkaline conditions for the ORR process to occur..$^{38}$ In particular, in such a structure, the catalytic activity strongly correlates with the ability of B-site cations to adopt different valence states, which leads to the formation of redox couples at the potential of oxygen reduction. ${ }^{39}$ The partial substitution of $\mathrm{La}^{3+}$ by an alkaline earth element (i.e., $\mathrm{Sr}^{2+}$ and $\mathrm{Ba}^{2+}$ ) or a lanthanide with a different valence at the A site introduces oxygen nonstoichiometry into the perovskite structure, leading to improved oxygen mobility. ${ }^{40-43}$ This substitution also results in cation vacancies and the formation of high-valence $M$ cations, facilitating the electron transfer to the oxygen and making perovskite-type structure materials promising candidates for ORR catalysis in alkaline medium. ${ }^{44}$

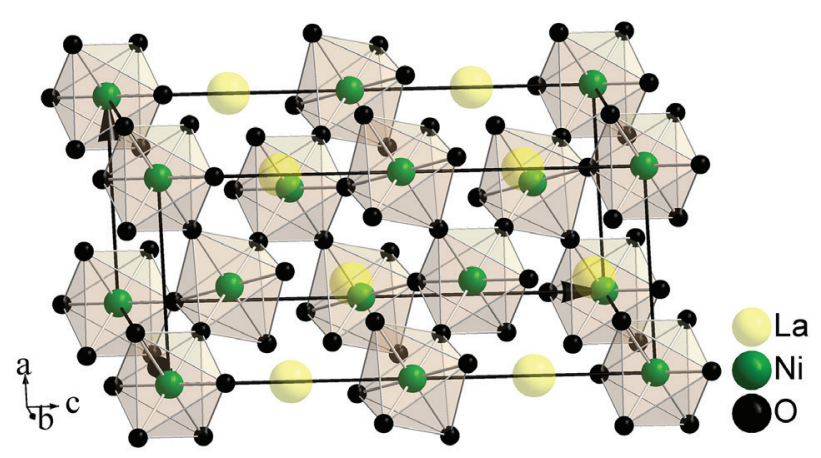

Figure 1. Schematic representation of the perovskite-type structure.

As the La-based perovskite oxides have low electrical conductivity, the addition of conducting agents, such as carbon black, carbon nanotubes or graphene oxide, is an efficient strategy to facilitate electron transfer during the ORR. Various studies reported in the literature ${ }^{19,28,45-51}$ have confirmed that the mixture of conducting agents to perovskite oxides promotes improvements in their physical and electronic properties, leading to an increase in the ORR efficiency when compared to the oxides only. Even if a carbon support is added to the perovskite material for enhancing its practical use as an ORR electrocatalyst, improved performance can be achieved by partial substitution of La in the A-site. For instance, structural defects/vacancies can be promoted in perovskites by introducing ions at the A-site, thus tuning the ORR activity.

Accordingly, herein we demonstrate our efforts to obtain new La-based substituted perovskite oxides, $\mathrm{La}_{0.6} \mathrm{M}_{0.4} \mathrm{Ni}_{0.6} \mathrm{Cu}_{0.4} \mathrm{O}_{3}(\mathrm{M}=\mathrm{Ag}, \mathrm{Ba}$, and $\mathrm{Ce})$, which have never been reported before as catalysts for ORR in alkaline solution. The main interest was to investigate the effect of partially substituting La by cations (M) in a host matrix of $\mathrm{LaNiO}_{3}(\mathrm{LN})$ on the electrocatalytic performance of these oxides towards the ORR in alkaline medium. The structure and intrinsic ORR catalytic activity of the synthesized oxides were characterized and studied by powder $\mathrm{X}$-ray diffraction (XRD), rotating disk electrode (RDE) voltammetry and scanning electrochemical microscopy (SECM).

\section{Experimental}

\section{Catalyst synthesis}

$\mathrm{La}_{0.6} \mathrm{M}_{0.4} \mathrm{Ni}_{0.6} \mathrm{Cu}_{0.4} \mathrm{O}_{3}(\mathrm{M}=\mathrm{Ag}, \mathrm{Ba}$, and $\mathrm{Ce}$, denoted as LANC, LBNC, and LCNC, respectively) perovskites were synthesized according to the Pechini method, ${ }^{52}$ using the following reagents: $\mathrm{La}\left(\mathrm{NO}_{3}\right)_{3} \cdot 6 \mathrm{H}_{2} \mathrm{O}(\geq 99 \%), \mathrm{AgNO}_{3}$ $(\geq 99.8 \%)$ and $\mathrm{Ba}\left(\mathrm{NO}_{3}\right)_{2}(\geq 99 \%)$ that were purchased from Merck KGaA (Darmstadt, Germany). $\mathrm{C}_{4} \mathrm{H}_{6} \mathrm{NiO}_{4} \cdot 4 \mathrm{H}_{2} \mathrm{O}$ ( $\geq 99 \%), \mathrm{Ce}\left(\mathrm{NO}_{3}\right)_{3} \cdot 6 \mathrm{H}_{2} \mathrm{O}(\geq 99 \%), \mathrm{Cu}\left(\mathrm{NO}_{3}\right)_{2} \cdot 3 \mathrm{H}_{2} \mathrm{O}$ $(\geq 98 \%)$, anhydrous citric acid (CA) $(\geq 99.5 \%)$ and ethylene glycol (EG) $(\geq 99 \%)$, were purchased from Sigma-Aldrich Chemical Company (St. Louis, MO, USA). All reagents were used as received. Initially, CA and EG were dissolved in high-purity deionized water $(18.2 \mathrm{M} \Omega \mathrm{cm})$ obtained from a Milli-Q water purification system (Millipore, Bedford, MA, USA) at $353 \mathrm{~K}$ under constant stirring. Then, stoichiometric amounts of the precursor salts were added to this solution to complete the desired stoichiometry. The molar ratio of $\mathrm{CA} /$ metal cations was fixed at $1.8: 1$, while the mass ratio of $\mathrm{CA} / \mathrm{EG}$ was adjusted to $60: 40$. The solvent was evaporated from the solutions resulting in a viscous resin, which was heat-treated in a furnace EDG 3000 (São Carlos, Brazil) at $393 \mathrm{~K}$ for $24 \mathrm{~h}$ and then calcined at $1023 \mathrm{~K}$ for $2 \mathrm{~h}$ under air atmosphere.

\section{X-ray diffraction characterization}

The perovskite oxides were characterized at room temperature using powder diffraction for phase identification with a diffractometer (Rigaku Smartlab, Tokyo, Japan), using a $\mathrm{Cu} \mathrm{K} \alpha$ radiation in Bragg-Brentano reflection geometry. The diffraction patterns were recorded by continuous scanning in the $2 \theta$ range of $5-80^{\circ}$ with an interval of $0.02^{\circ}$. The treatment of the data was carried out by the Rietveld method. ${ }^{53}$

\section{Electrodes preparation}

Perovskite and carbon modified electrodes were prepared by a drop-casting procedure over a rotating disk electrode (RDE), consisting of a glassy carbon (GC) disk electrode (GC, $5.61 \mathrm{~mm}$ diameter, $0.2475 \mathrm{~cm}^{2}$ area) model AFMSFX (Pine Research, Durham, NC, USA). Firstly, 
the GC electrode was pre-polished with $0.5 \mu \mathrm{m} \alpha-\mathrm{Al}_{2} \mathrm{O}_{3}$ suspension from Merck KGaA (Darmstadt, Germany), on a polishing cloth for further sonication in ethanol from Sigma-Aldrich Chemical Company (St. Louis, MO, USA) for $5 \mathrm{~min}$. The electrode was then rinsed with high-purity deionized water and dried before each test. After that, each perovskite catalyst was mixed with carbon (TIMCAL KS6L from C-NERGY ${ }^{\mathrm{TM}}$, Westlake, $\mathrm{OH}, \mathrm{USA}$ ) at a mass ratio of $5: 1$. The catalyst suspensions were prepared by sonication of a mixture of the perovskite oxide (5 mg), carbon (1 mg), Nafion solution (5 wt.\%) from Sigma-Aldrich Chemical Company (St. Louis, MO, USA) $(20 \mu \mathrm{L})$, high-purity deionized water $(490 \mu \mathrm{L})$ and ethanol $(490 \mu \mathrm{L})$ for at least one hour to generate a homogeneous ink. Finally, an $8 \mu \mathrm{L}$ aliquot of the catalyst ink was dropped onto the surface of the GC substrate, yielding an approximate catalyst loading of $141 \mu \mathrm{g} \mathrm{cm}^{-2}$. Then, the modified electrode was left to dry before the electrochemical experiments. A similar procedure was employed to prepare GC-modified electrodes containing only the secondary phases (identified as $\mathrm{NiO}, \mathrm{La}_{2} \mathrm{NiO}_{4}, \mathrm{La}_{2} \mathrm{O}_{3}, \mathrm{CuLaO}_{2}$, and $\mathrm{Ag}$, see Table $\mathrm{S} 1$, Supplementary Information (SI) section).

\section{Electrochemical measurements}

Electrochemical measurements were carried out at room temperature in a three-electrode electrochemical cell in an RDE configuration using an Autolab PGSTAT204 potentiostat (Metrohm, Utrecht, The Netherlands). A Pt bar and an $\mathrm{Ag} / \mathrm{AgCl} /$ saturated $\mathrm{KCl}$ (Sigma-Aldrich Chemical Company (St. Louis, MO, USA)) electrode were used as counter and reference electrodes, respectively. A $0.1 \mathrm{~mol} \mathrm{~L}^{-1}$ $\mathrm{KOH}$ aqueous solution from Sigma-Aldrich Chemical Company (St. Louis, MO, USA) used as electrolyte was saturated with $\mathrm{O}_{2}$ from Oxilúmen (São Paulo, Brazil) for ca. 30 min before each study. This solution was maintained under an $\mathrm{O}_{2}$ atmosphere throughout the entire experiment. The potential of the $\mathrm{Ag} / \mathrm{AgCl} /$ saturated $\mathrm{KCl}$ reference electrode was converted to the reversible hydrogen electrode $(\mathrm{RHE}), \mathrm{E}(\mathrm{RHE})=\mathrm{E}(\mathrm{Ag} / \mathrm{AgCl})+0.982 \mathrm{~V}$ $\left(0.1 \mathrm{~mol} \mathrm{~L}^{-1} \mathrm{KOH}, 298 \mathrm{~K}\right) .^{54}$ Cyclic voltammetry curves were recorded from 0.2 to $1.2 \mathrm{~V} v$ s. RHE in Ar-saturated and $\mathrm{O}_{2}$-saturated electrolytes at $20 \mathrm{mV} \mathrm{s}^{-1}$. For ORR studies, linear sweep voltammetry (LSV) curves were recorded at different electrode rotation rates $(200,400,600,900$, $1200,1600 \mathrm{rpm}$ ) in the oxygen-saturated $0.1 \mathrm{~mol} \mathrm{~L}^{-1} \mathrm{KOH}$ solution at the same potential range and scan rate of $5 \mathrm{mV} \mathrm{s}^{-1}$. Kinetic parameters regarding ORR, such as electron transfer number and kinetic current density, were determined using the Koutecky-Levich (K-L) relationship, ${ }^{55}$ which is presented in equation 1 :

$$
\begin{aligned}
& \frac{1}{\mathrm{i}_{\mathrm{d}}}=\frac{1}{\mathrm{i}_{\mathrm{k}}}+\frac{1}{\mathrm{i}_{\mathrm{dl}}}=\frac{1}{\mathrm{i}_{\mathrm{k}}}+\frac{1}{\mathrm{~B}} \omega^{-1 / 2} \\
& \mathrm{i}_{\mathrm{k}}=\mathrm{nFAkC}_{\mathrm{O}_{2}} \\
& \mathrm{~B}=0.62 \mathrm{nFC}_{\mathrm{O}_{2}} \mathrm{D}_{\mathrm{O}_{2}}^{2 / 3} v^{-1 / 6}
\end{aligned}
$$

where $i_{d}, i_{k}$ (equation 2), and $i_{d l}$ are the measured disk current density, kinetic current density, and diffusion limiting current density, respectively. Furthermore, $\mathrm{n}$ is the number of electrons in the ORR, $\mathrm{F}$ is the Faraday constant $\left(\mathrm{F}=96,485 \mathrm{C} \mathrm{mol}^{-1}\right)$, $\mathrm{A}$ is the area of the disk electrode $\left(\mathrm{A}=0.2475 \mathrm{~cm}^{2}\right), \mathrm{C}_{\mathrm{O}_{2}}$ is the oxygen concentration $\left(\mathrm{C}_{\mathrm{O}_{2}}=1.21 \times 10^{-6} \mathrm{~mol} \mathrm{~cm}-3\right), \mathrm{D}_{\mathrm{O}_{2}}$ is the oxygen diffusion coefficient $\left(\mathrm{D}_{\mathrm{O}_{2}}=1.86 \times 10^{-5} \mathrm{~cm}^{2} \mathrm{~s}^{-1}\right), v$ is the kinematic viscosity $\left(v=0.01 \mathrm{~cm}^{2} \mathrm{~s}^{-1}\right), \omega$ is the electrode rotation rate $\left(\mathrm{rad} \mathrm{s}^{-1}\right)$, and $\mathrm{k}$ is the rate constant for the ORR. The term $\mathrm{B}$ in equation 3 is the slope obtained from the Koutecky-Levich (K-L) plot, used to determine the number of electrons involved in the ORR.

For the SECM images, an Autolab PGSTAT 128N bipotentiostat was used in a Sensolytics (Sensolytics, Bochum, Germany) SECM working station coupled to an inverted microscope Axio Vert. A1 (Zeiss, Jena, Germany). A platinum disk-shaped microelectrode with a radius of $4.5 \mu \mathrm{m}$ was used as an SECM tip, and $\mathrm{Ag} / \mathrm{AgCl} / \mathrm{saturated} \mathrm{KCl}$ was used as a reference electrode. All electrochemical images were recorded in an oxygensaturated $0.1 \mathrm{~mol} \mathrm{~L}^{-1} \mathrm{KOH}$ solution. During SECM experiments, $\mathrm{O}_{2}$ was continuously purged into the protected volume above the solution.

\section{Results and Discussion}

\section{Structural characterization}

XRD patterns of the substituted perovskite oxides (Figure 2a) show the formation of crystalline structures evidenced by a regular group of peaks at different angles, which arise from a particular set of reflections. All crystal structures of the samples were refined by the Rietveld method using the General Structure Analysis System (GSAS) software. ${ }^{56}$ The input data of the theoretical model were those available in the Inorganic Crystal Structure Database (ICSD) (ICSD codes: 84933, 44387, 16025, 9866, 69172, 68459, and 18102). ${ }^{57-63}$ The refinement results showed a perovskite phase with rhombohedral symmetry and space group of $\mathrm{R} \overline{3} \mathrm{ch}$ in all oxides (attributed to the host matrix), besides allowing quantifying other crystalline phases (Table S1 and Figure S1, SI section). Figures 2b, 2c, and $2 \mathrm{~d}$ show the Rietveld plots obtained for LANC, LBNC, and LCNC, respectively. The residual pattern reveals a good 
fit between the theoretical and observed X-ray patterns, noted by the small variation along the diffraction angle. For instance, Ba and Ce partially occupy the crystallographic site A together with La in LBNC and LCNC. In contrast, site $\mathrm{B}$ is partially occupied by $\mathrm{Cu}$ and $\mathrm{Ni}$ in all substituted oxides. All Ag is found segregated as an additional phase in LANC (Figure 2b). In a perovskite-type structure, site $A$ is located in a cubic center surrounded by an octahedral framework (sites B) (see Figure 1). ${ }^{37}$ Changes in its configuration produce chemical and structural defects, such as oxygen vacancies, lattice distortions, and grain boundaries, which in oxides can control the transport properties and can enhance the material reactivity. ${ }^{64-68}$ The Ag phase identified in LANC is beneficial for the enhancement of the catalytic activity, and such property will be discussed in detail later.

\section{Electrochemical ORR investigation}

In order to investigate the electrocatalytic activity of TIMCAL KS6L (Carbon), $\mathrm{La}_{0.6} \mathrm{Ag}_{0.4} \mathrm{Ni}_{0.6} \mathrm{Cu}_{0.4} \mathrm{O}_{3}$-Carbon
(LANC/Carbon), $\mathrm{La}_{0.6} \mathrm{Ba}_{0.4} \mathrm{Ni}_{0.6} \mathrm{Cu}_{0.4} \mathrm{O}_{3}-\mathrm{Carbon}$ (LBNC/Carbon), and $\mathrm{La}_{0.6} \mathrm{Ce}_{0.4} \mathrm{Ni}_{0.6} \mathrm{Cu}_{0.4} \mathrm{O}_{3}$-Carbon (LCNC/Carbon), cyclic voltammetry measurements were performed in a $0.1 \mathrm{~mol} \mathrm{~L}^{-1} \mathrm{KOH}$ solution saturated with $\mathrm{Ar}$ or $\mathrm{O}_{2}$ (Figure 3). In an Ar-saturated solution, all catalysts show no redox peaks in the potential range from 1.2 to $0.2 \mathrm{~V}$ vs. RHE. The cathodic peak corresponding to the reduction of oxygen is noticed at $0.68 \mathrm{~V}$ for LANC/Carbon, $0.59 \mathrm{~V}$ for LBNC/Carbon, $0.63 \mathrm{~V}$ for LCNC/Carbon, and 0.61 V for carbon electrodes. Based on such peak potential values, LANC/Carbon appeared to be the best catalyst among the samples, as the ORR takes place at more favorable conditions in such an alkaline medium.

Further investigations were performed by rotating disk electrode (RDE) experiments in $0.1 \mathrm{~mol} \mathrm{~L}^{-1} \mathrm{KOH}$ oxygensaturated solution, as shown in Figure 4. As one can see in Figure 4a (LSV curves), current density and onset potential values obtained with the GC electrode modified with carbon were similar to those found for LBNC/Carbon and LCNC/Carbon electrodes. On the other hand, the LANC/Carbon modified electrode showed the highest
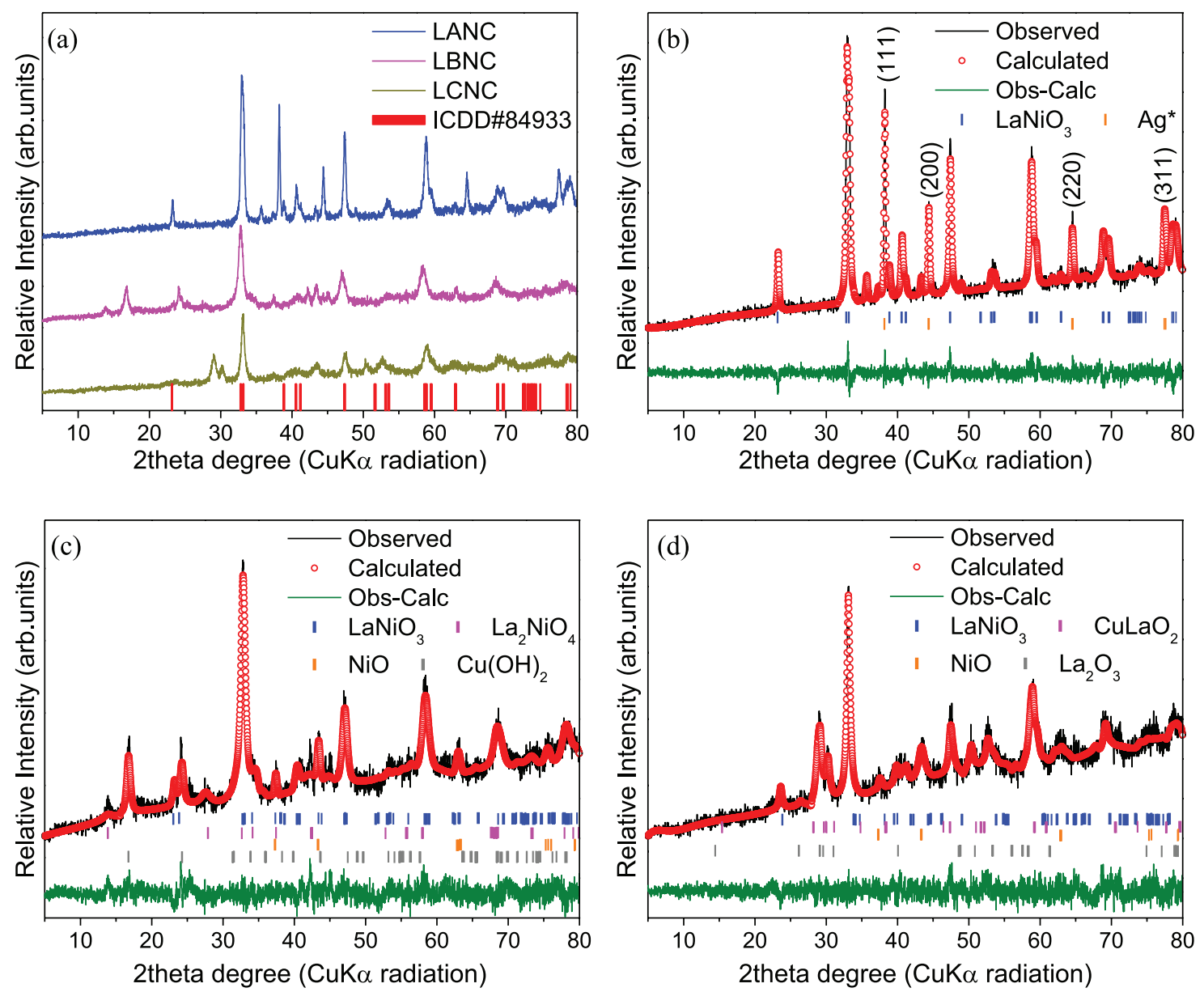

Figure 2. X-ray diffraction (XRD) patterns of LANC, LBNC, and LCNC (a) and Rietveld plots for LANC (inserted planes correspond to the crystallographic phase of $\mathrm{Ag})(\mathrm{b}),{ }^{59} \mathrm{LBNC}(\mathrm{c})$ and $\mathrm{LCNC}(\mathrm{d})$. 


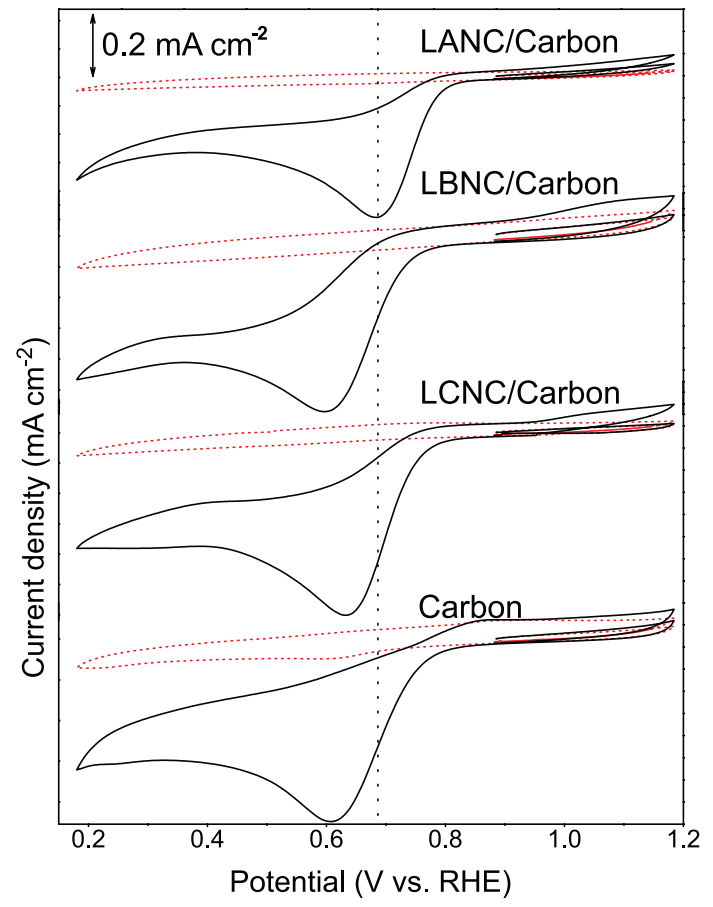

Figure 3. Cyclic voltammograms recorded with LANC/Carbon, LBNC/Carbon, LCNC/Carbon, and carbon modified GC electrodes in $0.1 \mathrm{~mol} \mathrm{~L}^{-1} \mathrm{KOH}$ solutions saturated with $\mathrm{Ar}$ (red curve) and $\mathrm{O}_{2}$ (black curve) at $298 \mathrm{~K}$ and at scan rate of $50 \mathrm{mV} \mathrm{s}^{-1}$.
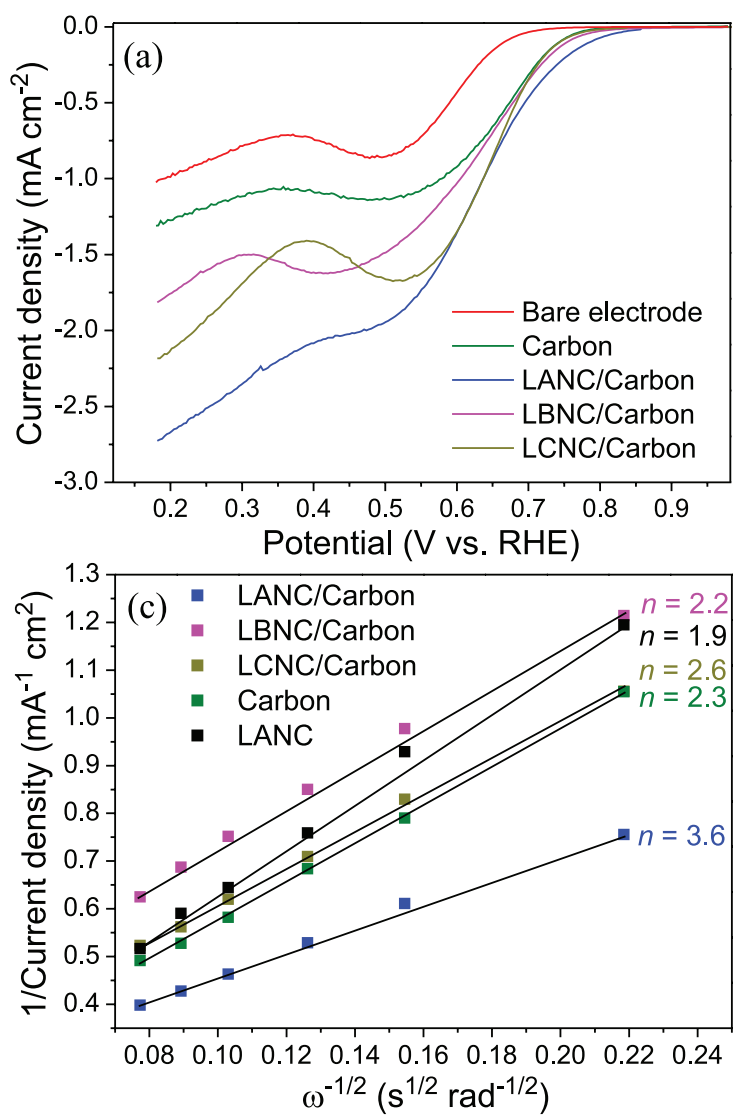

current and the most positive onset potential at 0.86 ( vs. RHE) compared to the other electrodes. Hence, the presence of the Ag phase provides more active sites on LANC, enhancing the catalytic activity toward the ORR. 69,70

Figure $4 \mathrm{~b}$ displays results of a control experiment with electrodes prepared with only the secondary phases identified by using the Rietveld method $\left(\mathrm{NiO}, \mathrm{La}_{2} \mathrm{NiO}_{4}\right.$, $\mathrm{La}_{2} \mathrm{O}_{3}, \mathrm{CuLaO}_{2}$, and Ag, see SI section). Accordingly, LSV curves recorded with such modified electrodes showed an electrocatalytic activity improvement compared with secondary phases + oxides. In particular, the Ag/Carbon exhibited a result comparable to that of LANC/Carbon, indicating that the $\mathrm{Ag}$ phase plays an important role in the ORR activity.

The appearance of a new cathodic process in $\mathrm{RDE}$ voltammograms of LANC/Carbon at potentials less positive than $0.4 \mathrm{~V}$ is only noticed at high rotation rates, as shown in Figure S2 (SI section). A single wave is noticed at lower rotation rates, which is the expected behavior for the ORR at surfaces containing Ag. ${ }^{71,72}$ Hence, it is suggested that the ORR process is masstransport controlled regarding the ORR at the potential region concerning the first wave. This can be attributed
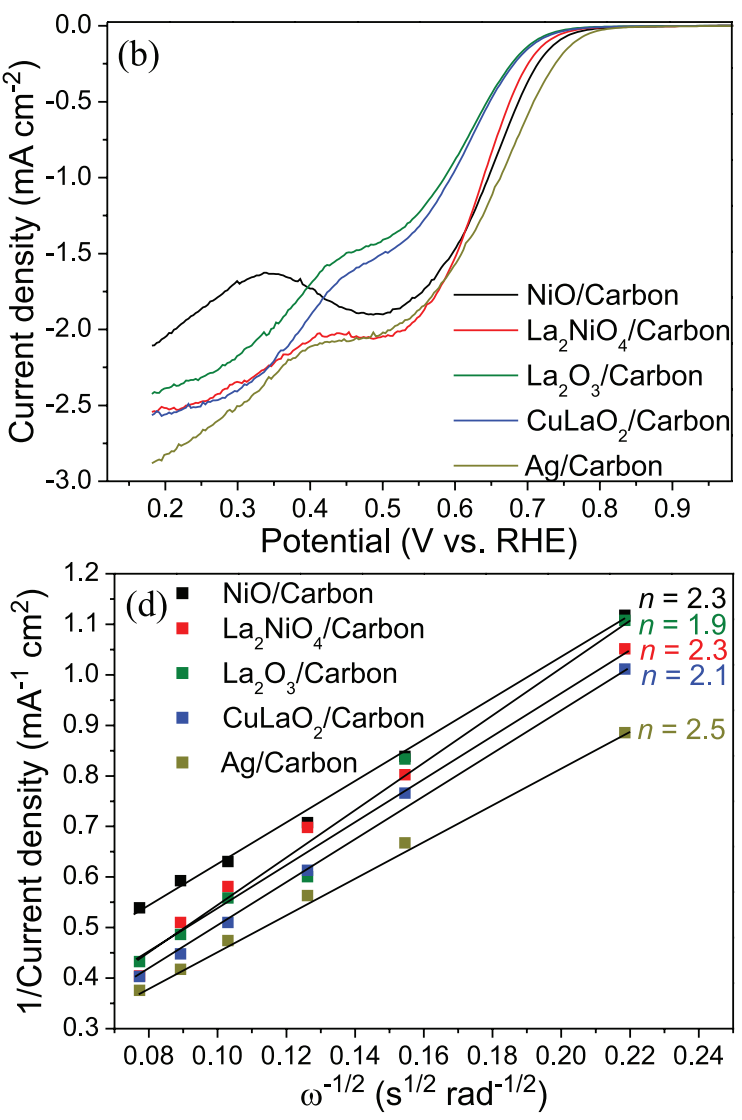

Figure 4. Linear sweep voltammograms recorded with GC (bare electrode) and GC electrodes modified with Carbon, LANC/Carbon, LBNC/Carbon and $\mathrm{LCNC} /$ Carbon (a) and with $\mathrm{NiO} /$ Carbon, $\mathrm{La}_{2} \mathrm{NiO}_{4} /$ Carbon, $\mathrm{La}_{2} \mathrm{O}_{3} /$ Carbon, $\mathrm{CuLaO}_{2} /$ Carbon, and $\mathrm{Ag} /$ Carbon (b) at 1600 rpm in oxygen-saturated $0.1 \mathrm{~mol} \mathrm{~L}^{-1} \mathrm{KOH}$ electrolyte and at scan rate of $5 \mathrm{mV} \mathrm{s}^{-1}$. Corresponding Koutecky-Levich plots at $0.25 \mathrm{~V} v s$. RHE are shown in panels (c) and (d). 
to a cooperative effect between $\mathrm{Ag}$ and the host matrix $\left(\mathrm{LaNiO}_{3}\right)$ in $\mathrm{LANC} / \mathrm{Carbon}$. Accordingly, due to the ability of the $\mathrm{LaNiO}_{3}$ to catalyze the first two-electron reduction process of oxygen, a $\mathrm{HO}_{2}^{-}$intermediate will be formed and such a species may diffuse along the surface or desorb and diffuse through the $\mathrm{Ag}$ or $\mathrm{Ag}-\mathrm{LaNiO}_{3}$ interface, where it can undergo disproportionation to oxygen for further reduction. ${ }^{73}$ If the disproportionation reaction of the $\mathrm{HO}_{2}^{-}$intermediate is very fast, then oxygen can be reduced in a pseudo four-electron reduction process. Further studies will be required to elucidate the current increase at high rotation rates at potentials less positive than $0.4 \mathrm{~V}$ vs. RHE.

Figures $4 \mathrm{c}$ and $4 \mathrm{~d}$ show the K-L plots in the masstransport limited region obtained from RDE experiments (see more RDE data in Figure S2, SI section) for LANC/Carbon, LBNC/Carbon, LCNC/Carbon, Carbon, LANC, and secondary phases, respectively. ${ }^{74}$ Symbols represent experimental data, and the straight lines are linear fitting results. The slope of the plot for each oxide and secondary phase was calculated, and then the number of electrons involved in the ORR process was obtained from RDE data (Figure S2, SI section) by using equation 3 . The average number of electrons $\mathrm{n}$ for LANC obtained from the K-L plot was only 1.9, whereas for LANC/ Carbon was 3.6. When compared to $\mathrm{Ag} /$ Carbon $(\mathrm{n}=2.5)$, which performs similarly in current density and onset potential, the pseudo four-electron pathway for LANC/ Carbon highlights the importance of this cooperation effect granting the latter a better overall catalytic performance. Hence, the fast disproportionation of hydroperoxide $\left(\mathrm{HO}_{2}^{-}\right)$ to $\mathrm{O}_{2}$ is a consequence of the intimate contact between the $\mathrm{Ag} / \mathrm{LaNiO}_{3}$ composite in LANC/Carbon. ${ }^{72,73}$

The synergistic effect between carbon and LANC can be better illustrated by analyzing the LSV curves in Figure 5, which shows the results of experiments carried out with bare carbon electrodes (without LANC), and with LANC and LANC/Carbon modified electrodes. Better performance in terms of both current and onset potential was noticed for the LANC/Carbon electrode, confirming the synergistic effect of such combination. ${ }^{75-82}$

Compared to some other perovskite-based electrodes, limiting current values noticed in LSV curves of Figure 4 are less remarkable. ${ }^{34,83,84}$ In particular, the catalytic performance observed for the LANC/Carbon electrode and $\mathrm{Ag} / \mathrm{Carbon}$ electrode can be attributed to the following key factors. The first one is the slow kinetics of peroxide formation, which is the rate-determining step regarding the first plateau of the LSV curve. The electroreduction of $\mathrm{O}_{2}$ to $\mathrm{H}_{2} \mathrm{O}_{2}$ involves a two coupled electron and proton transfer steps: ${ }^{85}$

$$
\begin{aligned}
& * \mathrm{O}_{2}+\mathrm{H}^{+}+\mathrm{e}^{-} \rightarrow * \mathrm{OOH} \\
& * \mathrm{OOH}+\mathrm{H}^{+}+\mathrm{e}^{-} \rightarrow *+\mathrm{H}_{2} \mathrm{O}_{2}
\end{aligned}
$$

where $*$ denotes the active site, and $* \mathrm{OOH}$ denotes the single adsorbed intermediate for $\mathrm{H}_{2} \mathrm{O}_{2}$ production. According to this model, an oxygen molecule is adsorbed on the active site, and then this absorbed $\mathrm{O}_{2}$ is reduced to its intermediate, $* \mathrm{OOH}$. Probably, the carbon atoms are responsible for the adsorption of oxygen, ${ }^{86,87}$ and as the TIMCAL KS6L carbon used in all experiments has a surface area of $20 \mathrm{~m}^{2} \mathrm{~g}^{-1}$, which is much lower than that of other conductive carbons (i.e., for Vulcan XC-72 the value is $\left.232 \mathrm{~m}^{2} \mathrm{~g}^{-1}\right),{ }^{88}$ this leads to lower density of active sites. Secondly, calcination temperature and particle size are well-known for their adverse effects on ORR ${ }^{89}$ It is likely that the synthesis method may have led to the formation of large silver particles with low surface area, which explains partly the observed current values and the undefined plateau in the LSV curves. Another possible explanation may be related to the presence of oxidative oxygen species $\left(\mathrm{O}_{2}^{2-} / \mathrm{O}^{-}\right),{ }^{90}$ which are closely related to the surface oxygen vacancies. Therefore, it seems the noticed poor ORR activity may also be associated with a low concentration of oxidative oxygen species on the surface of Ag particles. ${ }^{91}$

In addition to the catalytic performance, materials developed towards energy applications must be stable over time and retain its performance through long periods of operation. The stability of LANC/Carbon towards ORR was investigated (Figure S3, SI section), and only ca. 10\% decrease in current over $10,000 \mathrm{~s}$ was observed, which is comparable to the degradation rate reported for $\mathrm{Pt} / \mathrm{C}$ in alkaline medium (ca. 6\%). ${ }^{92}$

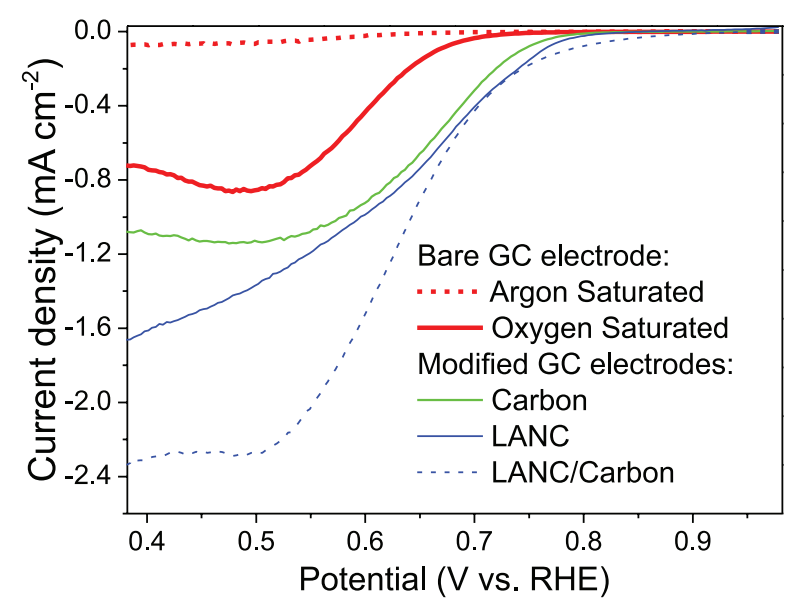

Figure 5. Comparative RDE (1600 rpm) linear sweep voltammograms recorded with GC (bare electrode) and GC electrodes modified with Carbon, LANC and LANC/Carbon electrodes in oxygen-saturated $0.1 \mathrm{~mol} \mathrm{~L}^{-1} \mathrm{KOH}$ electrolyte and of a GC electrode in argon-saturated $0.1 \mathrm{~mol} \mathrm{~L}^{-1} \mathrm{KOH}$ electrolyte. Scan rate of $5 \mathrm{mV} \mathrm{s}^{-1}$. 


\section{SECM studies}

To further investigate the performance of the Labased oxides towards ORR and to allow for a direct comparison between each material performance, a local redox competition SECM (RC-SECM) experiment was performed. Briefly, the tip and the sample "compete" with each other for the reduction, or oxidation, of the same species in an RC-SECM experiment, allowing for the visualization of catalytic effects on substrates and the comparison between different catalysts, as described elsewhere. ${ }^{93}$ A small sample of each of the three oxides/ carbon suspension (LANC/Carbon, LBNC/Carbon, and LCNC/Carbon) was drop-casted onto a thin transparent piece of indium-tin oxide (ITO) coated glass, forming a substrate for the RC-SECM experiment. The ITO coated glass not only works as a transparent substrate, allowing for easy positioning of the SECM tip over the substrate through an inverted optical microscope located bellow the SECM setup, but also as a conductive surface, modified with the La oxides, that can be biased for ORR. A representation of the SECM substrate can be found in Figure 6a. The SECM tip, a $4.5 \mu \mathrm{m}$ radius $\mathrm{Pt}$ microelectrode, was approached towards the substrate and held at a constant tip-substrate separation $(100 \mu \mathrm{m})$. With the tip biased at $0.18 \mathrm{~V} v s$. RHE (diffusion-limited oxygen reduction at a Pt surface) and the substrate polarized at $0.48 \mathrm{~V}$ vs. RHE (potential at which oxygen is reduced

(a) at the La-based oxides), the tip was scanned on a raster pattern across the three oxide samples (Figure 6b).

As both the SECM tip and the substrate are competing for oxygen reduction, when the tip is positioned over a site in the substrate where the oxygen reduction occurs more extensively (i.e., a catalytic site), a decrease in the reduction current recorded at the tip is expected, signaling a lower local oxygen concentration on the site. Comparatively, when the tip is over a site with less pronounced ORR activity, less oxygen is consumed by the substrate leading to a higher current at the tip. Hence, the extent of the tip current changes for different catalysts can provide information on the activity of such surfaces regarding the ORR.

The difference between the catalytic effects of the La-based oxides can be better seen when the tip current is normalized by the current recorded over the LANC/Carbon spot, which showed the highest catalytic effect towards ORR. As can be noticed by inspection of Figure $6 \mathrm{c}$, a decrease in the tip current was observed when the electrode was scanned across the oxide spots (Figure 6b), compared with the current recorded at the ITO substrate. This is expected as ITO has poor catalytic properties in comparison to metal and metal oxides. ${ }^{94,95}$ A more accentuated decrease in the tip current was observed in the bottom left-hand corner of Figure $6 \mathrm{c}$. This spot corresponds to the LANC/Carbon (Figure 6b), which showed the highest reduction current in the RDE experiments (see Figure 4a).

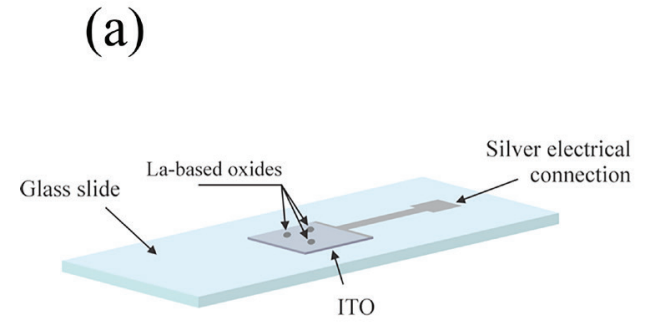

(b)
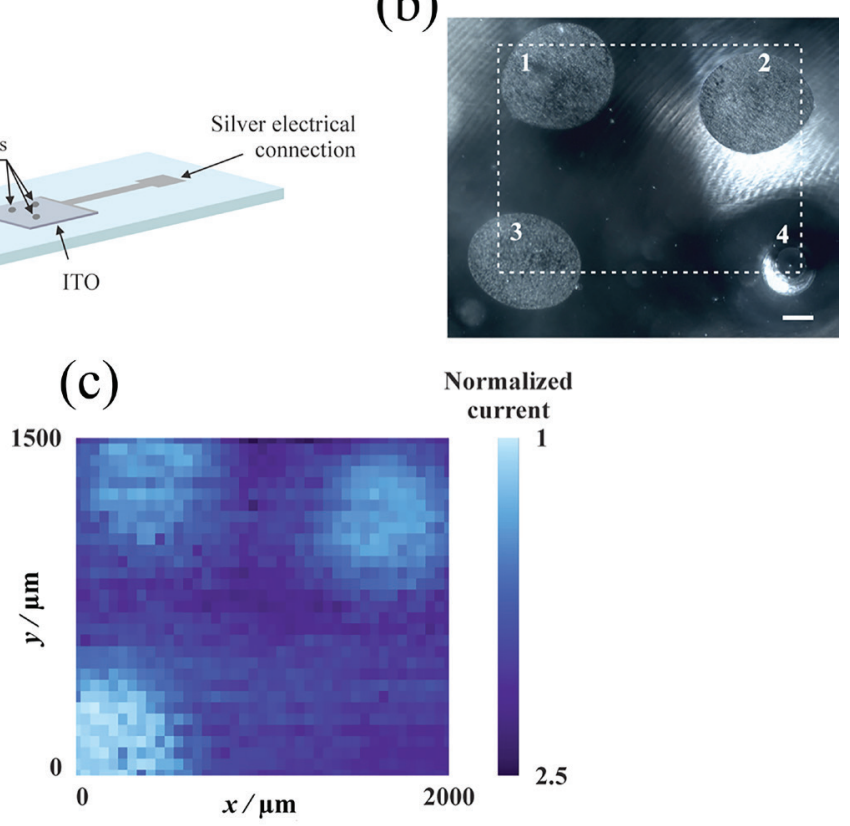

Figure 6. Representation of the SECM substrate with the ITO covered glass modified with the La-based oxides (a). Optical image of the SECM substrate after deposition of the oxides. Scale bar $=200 \mu \mathrm{m}$ : LBNC/Carbon (1), LCNC/Carbon (2), LANC/Carbon (3) and SECM tip (4). The dotted square shows the scanned area (b). RC-SECM normalized current map. $\mathrm{E}_{\text {sub }}=0.48 \mathrm{~V} v s$. RHE, $\mathrm{E}_{\text {tip }}=0.18 \mathrm{~V} v s$. RHE, pixel size $=50 \times 50 \mu \mathrm{m}$. Oxygen-saturated $0.1 \mathrm{~mol} \mathrm{~L}^{-1} \mathrm{KOH}$ solution (c). Potential values were measured against $\mathrm{Ag} / \mathrm{AgCl} / \mathrm{saturated} \mathrm{KCl}$. 
The other two spots in the image, corresponding to LBNC/Carbon and LCNC/Carbon, showed a similar decrease in current, indicating comparable catalytic effect, corroborating with LSV curves presented in Figure 4a. The normalized current recorded at the tip above the LBNC/Carbon and LCNC/Carbon spots is almost two-fold the one recorded over the LANC/Carbon spot, confirming the higher catalytic effect of the latter. It should be pointed out that although the LANC/Carbon spot was not entirely scanned, the drop-casting resulted in a homogenous surface with a homogenous performance towards ORR, as can be seen in Figure S4 (SI section). Hence, this should not pose a problem when comparing the activity between the oxides. This homogenous activity observed over the modified spots in Figures 6 and S4 (SI section) also demonstrates the stability of the oxides/carbon materials, which kept their catalytic performance throughout the length of the SECM images (approx. $3 \mathrm{~h}$ ).

\section{Conclusions}

In summary, we have synthesized La-based perovskite oxides simply through the Pechini method. Rietveld refinement allowed the total quantification of the crystallographic phases present in all oxide samples. Electrochemical investigations revealed that the ORR activity is strongly influenced by secondary phases and the doping metal used in the synthesis. The performance of the synthesized materials against the ORR followed the order: LANC/Carbon > LCNC/Carbon > LBNC/ Carbon, with LANC/Carbon showing good electrocatalytic activity and extended durability for the ORR in alkaline solution. This confirms the beneficial catalytic effect due to the presence of the Ag additional phase in LANC, which provides more active sites. The ORR seems to occur via a pseudo four-electron transfer pathway, which involves the formation of an $\mathrm{HO}_{2}^{-}$intermediate in a first step, followed by electrochemical reduction of the $\mathrm{O}_{2}$ molecules generated in the disproportionation of the hydroperoxide intermediate. Overall, we have demonstrated that the synthesis method, the presence of secondary phases and the use of a low surface area conductive carbon do not always lead to a pronounced synergistic effect between the phases, and must be considered in the development of new catalysts for ORR in alkaline medium from both activity and stability standpoints.

\section{Supplementary Information}

Supplementary data (additional XRD and electrochemistry data) is available free of charge at http://jbcs.sbq.org.br as PDF file.

\section{Acknowledgments}

The authors are grateful to the CNPq and FAPESP for financial support. Grants No. 159512/2015-8, 167437/2017-8, 303317/2013-2, 2015/02095-4 and 2014/223966, National Council of Technological and Scientific Development (CNPq), No. 2015/02095-4, 2015/20776-9 and 2014/22396-6, São Paulo Research Foundation (FAPESP).

\section{References}

1. Suntivich, J.; Gasteiger, H. A.; Yabuuchi, N.; Nakanishi, H.; Goodenough, J. B.; Shao-Horn, Y.; Nat. Chem. 2011, 3, 546.

2. Gonçalves, J. M.; da Silva, M. I.; Angnes, L.; Araki, K.; J. Mater. Chem. A 2020, 8, 2171.

3. Gasteiger, H. A.; Markovi, N. M.; Science 2009, 324, 48.

4. Whitesides, G. M.; Crabtree, G. W.; Science 2007, 315, 796.

5. Urbain, F.; Du, R.; Tang, P.; Smirnov, V.; Andreu, T.; Finger, F.; Divins, N. J.; Llorca, J.; Arbiol, J.; Cabot, A.; Morante, J. R.; Appl. Catal., B 2019, 259, 118055.

6. Lewis, N. S.; Nocera, D. G.; Proc. Natl. Acad. Sci. U. S. A. 2006, 103, 15729.

7. Kanan, M. W.; Nocera, D. G.; Science 2008, 321, 1072.

8. Park, H. S.; Yang, J.; Cho, M. K.; Lee, Y.; Cho, S.; Yim, S. D.; Kim, B. S.; Jang, J. H.; Song, H. K.; Nano Energy 2019, 55, 49.

9. Service, R. F.; Science 2009, 324, 1257.

10. de Oliveira, M. A. C.; Ficca, V. C. A.; Gokhale, R.; Santoro, C.; Mecheri, B.; D’Epifanio, A.; Licoccia, S.; Atanassov, P.; J. Solid State Electrochem. 2021, 25, 93.

11. Armand, M.; Tarascon, J. M.; Nature 2008, 451, 652.

12. Lu, Y. C.; Xu, Z.; Gasteiger, H. A.; Chen, S.; Hamad-Schifferli, K.; Shao-Horn, Y.; J. Am. Chem. Soc. 2010, 132, 12170.

13. Xu, Y.; Deng, P.; Chen, G.; Chen, J.; Yan, Y.; Qi, K.; Liu, H.; Xia, B. Y.; Adv. Funct. Mater. 2020, 30, 1906081.

14. Ge, X.; Sumboja, A.; Wuu, D.; An, T.; Li, B.; Goh, F. W. T.; Hor, T. S. A.; Zong, Y.; Liu, Z.; ACS Catal. 2015, 5, 4643.

15. Takimoto, D.; Sugimoto, W.; Yuan, Q.; Takao, N.; Itoh, T.; Duy, T. V. T.; Ohwaki, T.; Imai, H.; ACS Appl. Nano Mater. 2019, 2 , 5743.

16. Artyushkova, K.; Serov, A.; Rojas-Carbonell, S.; Atanassov, P.; J. Phys. Chem. C 2015, 119, 25917.

17. Takesue, Y.; Nakamura, M.; Hoshi, N.; Phys. Chem. Chem. Phys. 2014, 16, 13774.

18. Chisaka, M.; Suzuki, Y.; Iijima, T.; Sakurai, Y.; J. Phys. Chem. C 2011, 115, 20610.

19. Ji, Q.; Bi, L.; Zhang, J.; Cao, H.; Zhao, X. S.; Energy Environ. Sci. 2020, 13, 1408.

20. Zhang, J.; Ma, H.; Zhang, D.; Liu, P.; Tian, F.; Ding, Y.; Phys. Chem. Chem. Phys. 2008, 10, 3250.

21. Cai, Y.; Adzic, R. R.; Adv. Phys. Chem. 2011, $2011,530397$. 
22. Venarusso, L. B.; Bettini, J.; Maia, G.; J. Solid State Electrochem. 2016, 20, 1753.

23. Wang, D.; Liu, S.; Wang, J.; Lin, R.; Kawasaki, M.; Rus, E.; Silberstein, K. E.; Lowe, M. A.; Lin, F.; Nordlund, D.; Liu, H.; Muller, D. A.; Xin, H. L.; Abruña, H. D.; Nat. Commun. 2016, 7, 11941.

24. Yin, S.; Xie, Z.; Deng, X.; Xuan, W.; Duan, Y.; Zhang, S.; Liang, Y.; J. Electroanal. Chem. 2020, 856, 113707.

25. Wu, G.; Zelenay, P.; Acc. Chem. Res. 2013, 46, 1878.

26. Kalanur, S. S.; Seo, H. In Methods for Electrocatalysis, $1^{\text {st }}$ ed.; Inamuddin, S.; Boddula, R.; Asiri, A. M., eds.; Springer International Publishing: Cham, 2020.

27. Meadowcroft, D. B.; Nature 1970, 226, 847.

28. Suntivich, J.; Gasteiger, H. A.; Yabuuchi, N.; Shao-Horn, Y.; J. Electrochem. Soc. 2010, 157, B1263.

29. Rincón, R. A.; Masa, J.; Mehrpour, S.; Tietz, F.; Schuhmann, W.; Chem. Commun. 2014, 50, 14760.

30. Luo, H.; Wang, H.; Chen, X.; Huang, D.; Zhou, M.; Ding, D.; ChemCatChem 2020, 12, 2768.

31. Bockris, J. O.; J. Electrochem. Soc. 1984, 131, 290.

32. Rong, X.; Parolin, J.; Kolpak, A. M.; ACS Catal. 2016, 6, 1153.

33. Safakas, A.; Bampos, G.; Bebelis, S.; Appl. Catal., B 2019, 244 , 225.

34. Miao, H.; Wu, X.; Chen, B.; Wang, Q.; Wang, F.; Wang, J.; Zhang, C.; Zhang, H.; Yuan, J.; Zhang, Q.; Electrochim. Acta 2020, 333, 135566.

35. Zou, Z.; Ye, J.; Sayama, K.; Arakawa, H.; Nature 2001, 414, 625.

36. Garcia-Esparza, A. T.; Tymińska, N.; al Orabi, R. A. R.; le Bahers, T.; J. Mater. Chem. C 2019, 7, 1612.

37. West, A. R.; Basic Solid State Chemistry, $2^{\text {nd }}$ ed.; John Wiley \& Sons: Hoboken, USA, 1999.

38. Vielstich, W.; Yokokawa, H.; Gasteiger, H. A. In Handbook of Fuel Cells: Fundamentals Technology and Applications, vol. 1, $1^{\text {st }}$ ed.; Vielstich, W.; Lamm, A.; Gasteiger, H. A., eds.; John Wiley \& Sons: Hoboken, USA, 2009.

39. Jörissen, L.; J. Power Sources 2006, 155, 23.

40. Peña, M. A.; Fierro, J. L. G.; Chem. Rev. 2001, 101, 1981.

41. Ohno, Y.; Nagata, S.; Sato, H.; Solid State Ionics 1981, 3-4, 439.

42. Ferri, D.; Forni, L.; Appl. Catal., B 1998, 16, 119.

43. Zhu, H.; Zhang, P.; Dai, S.; ACS Catal. 2015, 5, 6370.

44. Yuan, X. Z.; Li, X.; Qu, W.; Ivey, D. G.; Wang, H.; ECS Trans. 2011, 35, 11.

45. Sunarso, J.; Torriero, A. A. J.; Zhou, W.; Howlett, P. C.; Forsyth, M.; J. Phys. Chem. C 2012, 116, 5827.

46. Xu, Y.; Tsou, A.; Fu, Y.; Wang, J.; Tian, J. H.; Yang, R.; Electrochim. Acta 2015, 174, 551.

47. Nishio, K.; Molla, S.; Okugaki, T.; Nakanishi, S.; Nitta, I.; Kotani, Y.; J. Power Sources 2015, 278, 645.
48. Elumeeva, K.; Masa, J.; Sierau, J.; Tietz, F.; Muhler, M.; Schuhmann, W.; Electrochim. Acta 2016, 208, 25.

49. Yusoff, F.; Mohamed, N.; Azizan, A.; Ab Ghani, S.; Int. J. Electrochem. Sci. 2016, 11, 5766.

50. Li, T.; Liu, J.; Jin, X.; Wang, F.; Song, Y.; Electrochim. Acta 2016, 198, 115.

51. Celorrio, V.; Dann, E.; Calvillo, L.; Morgan, D. J.; Hall, S. R.; Fermin, D. J.; ChemElectroChem 2016, 3, 283.

52. Pechini, M. P.; US pat. 33306971967.

53. IUCr Monographs on Crystallography; The Rietveld Method; Young, R. A., ed.; Oxford University Press: Oxford, UK, 1995.

54. Sun, X.; Zhang, Y.; Song, P.; Pan, J.; Zhuang, L.; Xu, W.; Xing, W.; ACS Catal. 2013, 3, 1726.

55. Bard, A. J.; Faulkner, L. R.; Electrochemical Methods: Fundamentals and Applications, $2^{\text {nd }}$ ed.; John Wiley \& Sons: Hoboken, USA, 2000.

56. Larson, A. C.; von Dreele, R. B.; General Structure Analysis System (GSAS), version 2018/1.0; Los Alamos Lab. Rep., Los Alamos, NM, USA, 1994.

57. Falcón, H.; Goeta, A. E.; Punte, G.; Carbonio, R. E.; J. Solid State Chem. 1997, 133, 379.

58. Spreadborough, J.; Christian, J. W.; J. Sci. Instrum. 1959, 36, 116.

59. Åsbrink, S.; Norrby, L. J.; Acta Crystallogr., Sect. B: Struct. Sci., Cryst. Eng. Mater. 1970, 26, 8.

60. Sasaki, S.; Fujino, K.; Takeuchi, Y.; Proc. Jpn. Acad., Ser. B 1979, 55, 43.

61. Takeda, Y.; Kanno, R.; Sakano, M.; Yamamoto, O.; Takano, M.; Bando, Y.; Akinaga, H.; Takita, K.; Goodenough, J. B.; Mater. Res. Bull. 1990, 25, 293.

62. Oswald, H. R.; Reller, A.; Schmalle, H. W.; Dubler, E.; Acta Crystallogr., Sect. C: Struct. Chem. 1990, 46, 2279.

63. Haas, H.; Kordes, E.; Z. Kristallogr. - Cryst. Mater. 1969, 129 , 259.

64. Wu, J.; Li, L. P.; Espinosa, W. T. P.; Haile, S. M.; J. Mater. Res. 2004, 19, 2366.

65. Bao, J.; Zhang, X.; Fan, B.; Zhang, J.; Zhou, M.; Yang, W.; Hu, X.; Wang, H.; Pan, B.; Xie, Y.; Angew. Chem., Int. Ed. 2015, 54, 7399 .

66. Paorici, C. In Encyclopedia of Materials: Science and Technology: Organic Crystals for Nonlinear Optics, $2^{\text {nd }}$ ed.; Jürgen Buschow, K.H.; Cahn, R.W.; Flemings, M. C.; Ilschner, B.; Kramer, E. J.; Mahajan, S.; Veyssière, P., eds.; Elsevier: Amsterdam, 2001.

67. Garbacz, H.; Królikowski, A. In Nanocrystalline Titanium, $1^{\text {st }}$ ed.; Garbacz, H.; Semenova, I.; Zherebtsov, S.; Motyka, M., eds; Elsevier: Amsterdam, 2019.

68. Li, L.; Feng, X.; Nie, Y.; Chen, S.; Shi, F.; Xiong, K.; Ding, W.; Qi, X.; Hu, J.; Wei, Z.; Wan, L.-J.; Xia, M.; ACS Catal. 2015, 5,4825 . 
69. Linge, J. M.; Erikson, H.; Kozlova, J.; Aruväli, J.; Sammelselg, V.; Tammeveski, K.; J. Solid State Electrochem. 2018, 22, 81.

70. Wang, Q.; Cui, X.; Guan, W.; Zhang, L.; Fan, X.; Shi, Z.; Zheng, W.; J. Power Sources 2014, 269, 152.

71. Lima, F. H. B.; Zhang, J.; Shao, M. H.; Sasaki, K.; Vukmirovic, M. B.; Ticianelli, E. A.; Adzic, R. R.; J. Phys. Chem. C 2007, 111, 404.

72. Singh, P.; Buttry, D. A.; J. Phys. Chem. C 2012, 116, 10656.

73. Slanac, D. A.; Lie, A.; Paulson, J. A.; Stevenson, K. J.; Johnston, K. P.; J. Phys. Chem. C 2012, 116, 11032.

74. Treimer, S.; Tang, A.; Johnson, D. C.; Electroanalysis 2002 , $14,165$.

75. Chen, Y. N.; Zhang, X.; Cui, H.; Zhang, X.; Xie, Z.; Wang, X. G.; Jiao, M.; Zhou, Z.; Energy Storage Mater. 2018, 15, 226.

76. Hu, J.; Shi, Z.; Su, C.; Lu, B.; Shao, Z.; Huang, H.; Electrochim. Acta 2018, 274, 40 .

77. Lee, D. U.; Xu, P.; Cano, Z. P.; Kashkooli, A. G.; Park, M. G.; Chen, Z.; J. Mater. Chem. A 2016, 4, 7107.

78. Wang, Z. L.; Xu, D.; Xu, J. J.; Zhang, X. B.; Chem. Soc. Rev. 2014, 43, 7746.

79. Zhou, S.; Liu, N.; Wang, Z.; Zhao, J.; ACS Appl. Mater. Interfaces 2017, 9, 22578.

80. Hazarika, K. K.; Goswami, C.; Saikia, H.; Borah, B. J.; Bharali, P.; Mol. Catal. 2017, 451, 153.

81. Kalubarme, R. S.; Park, G. E.; Jung, K. N.; Shin, K. H.; Ryu, W. H.; Park, C. J.; J. Electrochem. Soc. 2014, 161, A880.

82. Li, X.; Qu, W.; Zhang, J.; Wang, H.; J. Electrochem. Soc. 2011, 158, A597.

83. Retuerto, M.; Calle-Vallejo, F.; Pascual, L.; Lumbeeck, G.; Fernandez-Diaz, M. T.; Croft, M.; Gopalakrishnan, J.; Peña, M. A.; Hadermann, J.; Greenblatt, M.; Rojas, S.; ACS Appl. Mater. Interfaces 2019, 11, 21454.

84. Yuan, R.; He, Y.; He, W.; Ni, M.; Leung, M. K. H.; Energy Procedia 2019, 158, 5804.
85. Siahrostami, S.; Verdaguer-Casadevall, A.; Karamad, M.; Deiana, D.; Malacrida, P.; Wickman, B.; Escudero-Escribano, M.; Paoli, E. A.; Frydendal, R.; Hansen, T. W.; Chorkendorff, I.; Stephens, I. E. L.; Rossmeisl, J.; Nat. Mater. 2013, 12, 1137.

86. Wu, Y.; Muthukrishnan, A.; Nagata, S.; Nabae, Y.; J. Phys. Chem. C 2019, 123, 4590.

87. Guo, D.; Shibuya, R.; Akiba, C.; Saji, S.; Kondo, T.; Nakamura, J.; Science 2016, 351, 361.

88. https://www.imerys-graphite-and-carbon.com/?dl_ name=Carbon_Additives_for_the_Pos_Web21Feb19.pdf, accessed in November 2020.

89. Retuerto, M.; Pereira, A. G.; Pérez-Alonso, F. J.; Peña, M. A.; Fierro, J. L. G.; Alonso, J. A.; Fernández-Díaz, M. T.; Pascual, L.; Rojas, S.; Appl. Catal., B 2017, 203, 363.

90. Zhu, J.; Li, H.; Zhong, L.; Xiao, P.; Xu, X.; Yang, X.; Zhao, Z.; Li, J.; ACS Catal. 2014, 4, 2917.

91. Du, J.; Zhang, T.; Cheng, F.; Chu, W.; Wu, Z.; Chen, J.; Inorg. Chem. 2014, 53, 9106.

92. Yang, S.; Mao, X.; Cao, Z.; Yin, Y.; Wang, Z.; Shi, M.; Dong, H.; Appl. Surf. Sci. 2018, 427, 626.

93. Eckhard, K.; Chen, X.; Turcu, F.; Schuhmann, W.; Phys. Chem. Chem. Phys. 2006, 8, 5359.

94. Das, J.; Jo, K.; Jae, W. L.; Yang, H.; Anal. Chem. 2007, 79, 2790.

95. Zudans, I.; Paddock, J. R.; Kuramitz, H.; Maghasi, A. T.; Wansapura, C. M.; Conklin, S. D.; Kaval, N.; Shtoyko, T.; Monk, D. J.; Bryan, S. A.; Hubler, T. L.; Richardson, J. N.; Seliskar, C. J.; Heineman, W. R.; J. Electroanal. Chem. 2004, 565,311

Submitted: June 15, 2020 Published online: November 10, 2020 